\title{
Assessing sense of community at farmers markets: A systematic review
}

\author{
Jennifer Russomanno ${ }^{a}$ and Jennifer M. Jabson Tree ${ }^{b}$ \\ University of Tennessee
}

Submitted September 9, 2020 / Revised October 29, December 15, and December 17, 2020 /

Accepted December 17, 2020 / Published online April 6, 2021

Citation: Russomanno, J., \& Jabson Tree, J. M. (2021). Assessing sense of community at

farmers markets: A systematic review. Journal of Agriculture, Food Systems, and Community

Development, 10(2), 489-506. https://doi.org/10.5304/jafscd.2021.102.032

Copyright (C) 2021 by the Authors. Published by the Lyson Center for Civic Agriculture and Food Systems. Open access under CC-BY license.

\begin{abstract}
Farmers markets are valuable for reducing food insecurity and delivering healthy food options to populations living with low incomes. However, farmers markets have developed a reputation for being exclusive shopping spaces devoted to affluent, white shoppers. Sense of community (SOC), or a person's feelings of belonging at farmers markets, could be an important, underaddressed asset or barrier to farmers markets patronage for people living with low incomes. To document and describe how SOC influences customer engagement with farmers markets, we conducted a systematic review of published, peerreviewed literature following PRISMA guidelines. Systematic review protocol involved three stages: identifying peer-reviewed articles using key search terms, screening abstracts and articles for inclusion

a* Corresponding author: Jennifer Russomanno, DrPH, MPH, University of Tennessee.

Jennifer Russomanno is now Assistant Professor, Lincoln Memorial University; 9737 Cogdill Road; Knoxville, TN 37932 USA; +1-865-338-5722; Jennifer.russomanno@lmunet.edu

Jennifer M. Jabson Tree, PhD, MPH, Associate Professor, University of Tennessee; jabstree@utk.edu
\end{abstract}

and exclusion, and analyzing articles for SOC at farmers markets. Of the 24 articles included in the systematic review, 10 addressed SOC in farmers markets shoppers living with low incomes, 6 addressed SOC in farmers markets shoppers living with middle to high incomes, and 8 did not indicate the shoppers' income level. SOC served as both a barrier and facilitator to farmers markets patronage for all income levels. However, farmers markets shoppers who received federal food assistance reported a feeling of exclusion discouraging them from shopping at farmers markets. These negative experiences were more prominent among Black, Indigenous, and other People of Color (BIPOC) living with low incomes. SOC appears to be an important factor in determining who shops at farmers markets and the frequency with which they visit. Farmers markets managers should consider how to strengthen SOC to improve engagement with people living with low incomes, and more specifically, BIPOC living with low incomes.

\section{Keywords}

Farmers Market, Sense of Community, SNAP, Low-Income, Shopping Behaviors 


\section{Introduction}

Farmers markets are important community mechanisms for bringing affordable, healthy food options to populations living with low incomes (Appalachian Sustainable Agriculture Project, 2012; Briggs, 2010; Fisher, 1999; Markowitz, 2010). Accepting food assistance programs like the Supplemental Nutrition Assistance Program (SNAP) is one strategy that has been widely used by markets to attract shoppers living with low incomes and to promote their purchasing of affordable, healthy food options (Briggs, 2010; McGill, 2015; Young et al., 2013). As of December 2019, there were 8,788 farmers markets registered in the U.S. Department of Agriculture (USDA) National Farmers Market Directory (USDA, 2019b). Of those markets, 2,947 (33.5\%) were authorized to accept SNAP as an approved payment method, a 215\% increase over the number of farmers markets that were SNAPauthorized in 2009 (USDA, 2010).

SNAP redemption at farmers markets has seen significant growth in the past decade. In Fiscal Year (FY) 2009, SNAP redemption at farmers markets totaled US\$4.2 million. In FY 2017, that number grew to US $\$ 22.4$ million, an increase of 433\% (Farmers Market Coalition, 2020b). This increase can be attributed to the introduction of monetary incentive programs such as 'Double Up', where SNAP dollars are matched in value by farmers markets. For example, a SNAP recipient may redeem US $\$ 10.00$ of their SNAP benefits at a local farmers market, and, in turn, the market doubles this amount, giving the SNAP recipient a total of US $\$ 20.00$ to spend at the market.

Incentive programs at farmers markets appear to increase accessibility and consumption of locally sourced fruits and vegetables by shoppers living with low incomes (Briggs, 2010; McGill, 2015; Olsho et al., 2015; Young, Karpyn, Uy, Wich, \& Glyn, 2011; Young et al., 2013). Many farmers markets across the U.S. report significant increases in SNAP redemption with the implementation of incentive programs. Michigan's Fair Food Network has seen significant growth in SNAP redemption since the 2009 implementation of their 'Double Up' Incentive program. In 2007, less than US\$16,000 in SNAP benefits were redeemed at Michigan farmers markets. In 2016, because of their 'Double Up' program, Michigan farmers market SNAP sales increased to over US\$1.9 million (Fair Food Network, 2018). Similarly, Pennsylvania farmers markets reported a 375\% increase in SNAP redemption after the implementation of their Philly Food Bucks Program in 2010 (The Food Trust, 2018).

While incentive programs have proven successful in increasing farmers market SNAP redemption and self-reported fruit and vegetable consumption by people living with low incomes (Evans et al., 2012; Jilcott Pitts et al., 2013; Walkinshaw, Quinn, Rocha, \& Johnson, 2018), SNAP redemption at farmers markets continues to represent a small fraction $(<0.1 \%)$ of all SNAP transactions across the U.S. (Center on Budget and Policy Priorities, 2019). The lack of overall SNAP redemption at farmers markets indicates that additional barriers beyond monetary incentives may be dissuading people living with low incomes from shopping at farmers markets. Previous research suggests that spatial barriers including transportation (Freedman et al., 2016; Misyak, Ledlie Johnson, McFerren, \& Serrano, 2014; Racine, Smith Vaughn, \& Laditka, 2010) and limited operating times (Colasanti, Conner, \& Smalley, 2010; Farmer, Chancellor, Gooding, Shubowitz, \& Bryant, 2011; Freedman et al., 2016) as well as economic barriers such as perceived increased costs for goods (Colasanti et al., 2010; Flamm, 2011; Freedman et al., 2016; Ruelas, Iverson, Kiekel, \& Peters, 2012) limit farmers market participation by people living with low incomes. However, one concept that has been widely overlooked when assessing farmers market patronage is sense of community (SOC).

SOC experienced by shoppers living with low incomes at farmers markets could play an important role in retaining and improving SNAP redemption. 'Sense of Community' is defined as "a feeling that members have of belonging; a feeling that members matter to one another and to the group, and there is a shared faith that members' needs will be met through their commitment to be together" (McMillan \& Chavis, 1986, p. 9).

McMillan and Chavis theorize that sense of community and belonging are essential to civic participation, social identity, and community 
attachment. We believe that SOC is an important aspect of farmers markets and that, for some, farmers markets represent community centerpieces and central gathering spaces (Feagan \& Morris, 2009; Project for Public Spaces, 2013). Building and maintaining a welcoming environment and positive SOC could be an important factor in determining who shops at farmers markets and the frequency with which they visit.

Past research indicates that farmers markets are primarily attended by shoppers that meet select demographic criteria (middle- to high-income and predominately white), and the ways in which farmers markets are established, managed, and promoted are structured toward people who match these demographics (Alkon \& McCullen, 2011; Briggs, 2010; Colasanti et al., 2010; Rice, 2015). In a study assessing farmers markets as niche shopping experiences, DeLind (1993) concluded that marketing strategies used by farmers markets most often target an elite customer base. Additionally, in an ethnographic study assessing farmers markets in Northern California, Alkon and McCullen (2011) uncovered that many farmers market managers, vendors, and customers held notions of what farmers and community members should look like, which reflected visions of affluent, white people. These perceptions and beliefs, along with market implementation strategies, may translate into an unintended message that people living with low incomes are unwanted and unwelcome at farmers markets.

Shoppers living with low incomes and SNAP recipients are not a monolith; they are a racially and ethnically diverse group of individuals. According to a USDA report on the characteristics of SNAP recipients, over $40 \%$ of recipients are Black, Indigenous, and/or People of Color (BIPOC) (USDA, 2019a). If farmers markets are regarded as predominately white spaces, being BIPOC, lowincome, and a SNAP beneficiary could position shoppers to have unique perspectives and experiences that may not produce a positive sense of community or belonging at farmers markets. In fact, given the evidence about farmers markets implementation strategies, and vendor and customer beliefs, it is possible that BIPOC who are living with low incomes and receive SNAP benefits may have negative experiences that influence their likelihood of shopping at farmers markets.

According to community-based evidence, SOC is important to shopping behaviors and experiences. Plas and Lewis (1996) assessed the community development and urban planning of Seaside, Florida, and determined that a town strategically designed to induce high SOC and individual well-being positively influenced an individual's desire to shop in local stores, support local businesses, connect with neighbors, and participate in community events. Additionally, Muniz and O'Guinn (2001) found that individuals residing in one Midwestern neighborhood influenced one another to purchase particular brands of products (e.g., Saab, Apple, and Coca-Cola) and that purchasing the same products as their neighbors produced an important social bond within the community (Muniz \& O'Guinn, 2001). Following this evidence and McMillan and Chavis' theory of SOC, if farmers market shoppers experience positive SOC and feel included as members of the farmers market community, the likelihood of continued and more frequent support of the farmers market could be greater.

The empirical notion that SOC could relate to farmers market shopping behaviors of people living with low incomes is relatively new. There are only a few existing studies that reference SOC as one of many potential barriers or assets to farmers market usage (Baker, Hamshaw, \& Kolodinsky, 2009; Colasanti et al., 2010; Feagan \& Morris, 2009; Szmigin, Maddock, \& Carrigan, 2003), yet none have examined SOC as a standalone asset or barrier to farmers market participation. Our purpose was to conduct a review of farmers market literature and to summarize and document what is empirically known about SOC as an asset or barrier to farmers market usage for shoppers based on income level and race and/or ethnicity. To fulfill this purpose, we conducted a systematic review of published, peer-reviewed literature.

\section{Methods}

Preferred Reporting Items for Systematic Reviews and Meta-analyses (PRISMA) guidelines were followed for this systematic review. PRISMA guidelines provide an evidence-based set of 27 activities 
for conducting and reporting findings produced by systematic reviews of literature (Moher, Liberati, Tetzlaff, \& Altman, 2009). Our systematic review is registered with and can be reviewed at PROSPERO, an international registry of systematic reviews, under protocol registration number CRD42019118234. The review protocol involved three stages. A complete illustration of article selection procedures is included as Figure 1. Articles were identified by applying specific search terms in online databases in addition to a snowball technique when reviewing full-text articles. primary qualitative or quantitative data, and included the key terms "sense of community" and/ or other terms that are a logical indicator of or proxy for SOC including, but not limited to, social factors, social benefits, social interaction, social embeddedness, community ties, and cultural barriers. These key terms were selected because of their similarity to SOC as defined by McMillian and Chavis (1986) (Figure 2). During the title review process, 20 studies were excluded from further analysis as they were not published in peer-reviewed journals. An additional 191 articles were excluded based on

\section{Stage 1}

In September and October 2018, peer-reviewed articles were identified using three online databases, PubMed, PsycINFO, and Google Scholar, with no specific publication date range selected. Defined search terms used in each database included the words farmers market paired with each of the following: low-income, barriers and lowincome, community, $S N A P$, and sense of community. This search resulted in a return of 475 articles, with 352 remaining after duplicates were removed. Documentation of the search results, including search terms, is included as Table 1.

\section{Stage 2}

The remaining 352 articles were screened for inclusion based on titles and abstracts. Inclusion criteria included: written in English, published in a peer-reviewed journal, reported on

\section{Figure 1. Systematic Review Process for Article Selection}

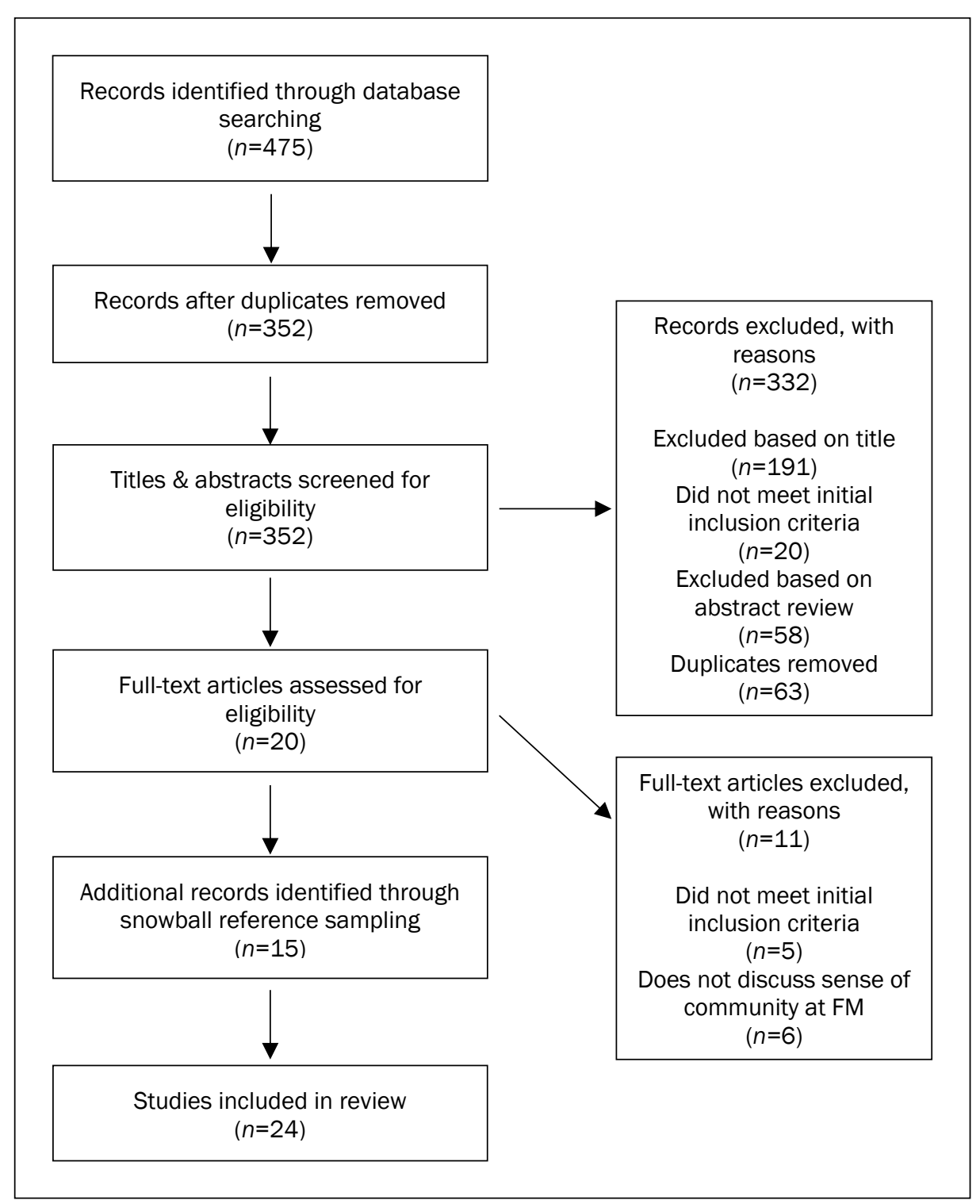


Table 1. Systematic Review Search Results

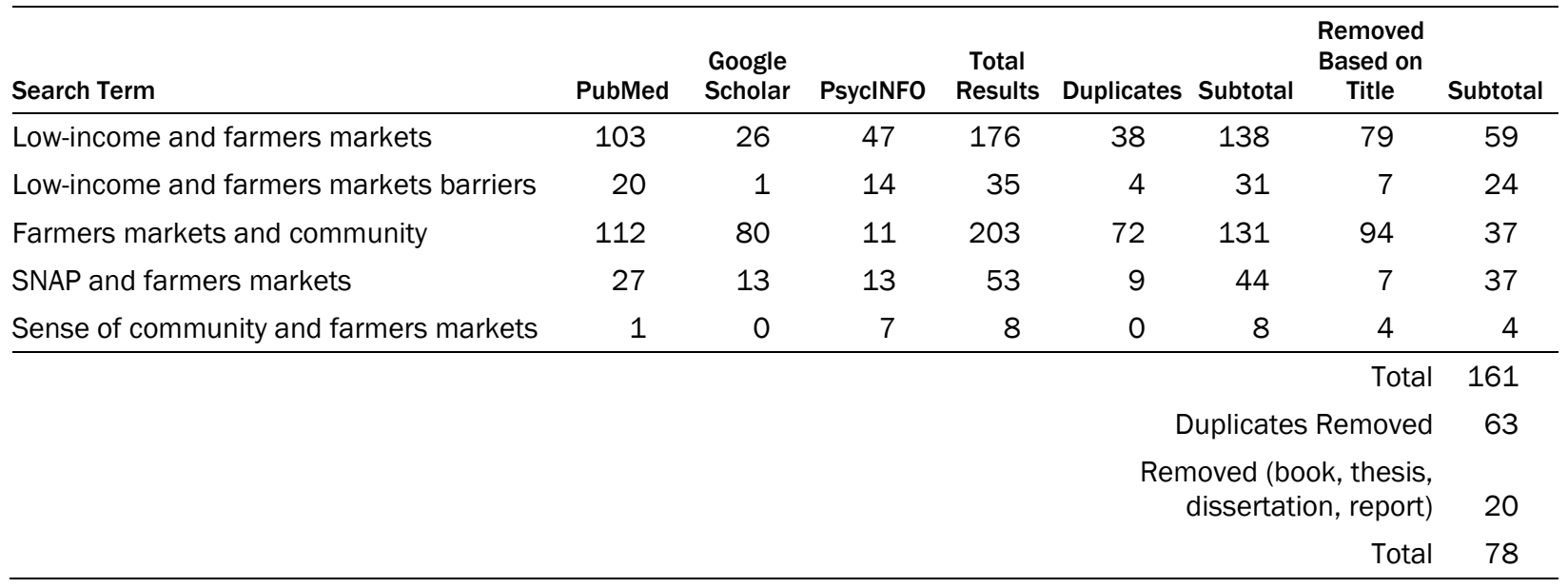

article title and lack of relevance to SOC among farmers market shoppers.

The remaining 78 article abstracts were screened by two reviewers (JR and JJT). Two independent reviewers were used to screen potential abstracts for inclusion to mitigate the risk for individual bias in the review process. Review protocol required reviewers to include articles for full-text review if the abstract contained any of the identified key words or phrases that represented SOC. Discrepancies between reviewers were discussed until consensus was achieved. Abstract screening resulted in the identification of 20 articles for full-text analysis.

\section{Stage 3}

The remaining 20 articles were reviewed by the first author. Inclusion criteria for full-text review included the criteria outlined in Stage 2 and if key terms for SOC were discussed in the results section. Full-text review resulted in the exclusion of an additional 11 articles. Of the 11 excluded articles, five were excluded because they did not involve primary qualitative or quantitative data, and six did not include SOC among farmers market shoppers in the results section.

During the full-text review, an additional 15 articles were identified using a snowball technique of article reference sections (Horsley, Dingwall, \& Sampson, 2011; Wohlin, 2014) that involved reviewing the reference lists of included publications to see if these references produce yet unidentified publications that could be eligible for review (Horsley et al., 2011). A total of 24 articles were included in the final sample for analysis.

After the full-text review was complete, all publications were grouped into two categoriesSOC among farmers market shoppers living with low incomes and SOC among farmers market shoppers living with middle to high incomes. Studies including shoppers living with low incomes were identified as such based on authors' disclosure that either participants had low incomes

\section{Figure 2. Key Words Identified in Abstracts}

$\begin{array}{ll}\text { Social embeddedness } & \text { Community involvement } \\ \text { Social interaction } & \text { Interpersonal relationships } \\ \text { Social participation } & \text { Satisfaction with farmers markets } \\ \text { Social access } & \text { Relationships } \\ \text { Social benefits } & \text { Communication } \\ \text { Social networking } & \text { Shopping experiences } \\ \text { Support for local agriculture } & \text { Social events and activities } \\ \text { Community } & \text { Local identity } \\ \text { Prejudice/discrimination } & \text { Sense of community } \\ \text { Perceptions of markets } & \text { Community values } \\ \text { Cultural barriers } & \text { Community ties }\end{array}$


and/or participated in one or more income-based federal food assistance programs. Studies including shoppers living with middle to high incomes were identified from the authors' disclosure that participants came from middle to high income households or based on the average reported income of participants.

All publications that presented SOC proxy terms or phrases were included in the review and any missing demographic characteristics were labeled as 'not recorded' (NR). Study population and demographic information included in the review were sample size, study location, income level of participants (high, middle, or low), and majority race and/or ethnicity of participants. Direct quotes related to SOC proxy terms or phrases were documented from each study and were included in the review.

This project did not involve human subjects and did not require approval by the University of Tennessee Institutional Review Board.

\section{Results}

Table 2 summarizes the 24 articles included in this review. Of the 24 articles, $41.7 \%(n=10)$ explored SOC among farmers market shoppers living with low incomes, $25 \%(n=6)$ explored SOC among farmers market shoppers living with middle to high incomes, and 33.3\% $(n=8)$ did not report income. For articles that explored SOC among populations living with low incomes, all 10 disclosed that study participants were recipients of one or more income-based federal food assistance programs. For articles that explored SOC among shoppers living with middle to high incomes, five (Alonso \& O’Neill, 2011; Baker et al., 2009; Eastwood, Brooker, \& Gray, 1999; Feagan, Morris, \& Krug, 2004; Feagan \& Morris, 2009) disclosed that participants had middle to high incomes based on their city or region, and one (Hunt, 2007) disclosed the average income of participants was over US $\$ 75,000$, which is nearly $600 \%$ of the U.S. Federal Poverty Level for a household of one. Regarding race and ethnicity, 25\% $(n=6)$ included farmers market shopping experiences of BIPOC, while $37.5 \%$ included experiences of primarily white farmers market shoppers. Additionally, $41.6 \%(n=10)$ of the studies did not report the race or ethnicity of their population.

Most articles $(75 \%, n=18)$ focused on populations in the U.S., with concentrations in the Western $(n=6)$, Southeast $(n=4)$, Midwest $(n=4)$, and Northeast $(n=3)$ regions of the country. One study, by Buman et al. (2015), only indicated that it took place in a "large U.S. based metropolitan city" but did not provide a specific location. Studies from outside the U.S. $(20.8 \% ; n=5)$ focused on populations in Canada $(n=3)$ and Australia $(n=2)$. One study conducted by Garner (2015) did not provide a study location. A plurality of studies $(41.7 \%$; $n=10)$ were quantitative, while $33.3 \%(n=8)$ were qualitative, and $25 \%(n=6)$ utilized mixed methods. The median sample size for all studies was 198 participants (range $=14$ to 1,016 ). The wide range in sample sizes was related to each study's design, with qualitative studies including smaller sample sizes compared with quantitative studies.

\section{Description of SOC in the Included Articles}

In the 24 articles, authors operationalized SOC using a range of proxy terms and descriptors that fit within McMillan and Chavis' (1986) definition of SOC. In $50 \%$ of the articles $(n=12)$ (Alonso \& O’Neill, 2011; Baker et al., 2009; Buman et al., 2015; Dailey et al., 2015; R. Feagan et al., 2004; Feagan \& Morris, 2009; Garner, 2015; Grace, Grace, Becker, \& Lyden, 2007; Hunt, 2007; McGuirt, Ward, Elliott, Bullock, \& Jilcott Pitts, 2014; O'Kane, 2016; Payet, Gilles, \& Howat, 2005), the authors described 'social interactions' among community members, farmers market vendors, or other patrons as a primary barrier to or facilitator of farmers market usage. Other aspects of SOC discussed in the articles included 'social and community connectedness' $(29.2 \%, n=7$ ) (Alkon \& McCullen, 2011; Alonso \& O'Neill, 2011; Freedman et al., 2018; Garner, 2015; A. J. Johnson, 2013; O'Kane, 2016; Savoie Roskos, 2017), 'social benefits' (12.5\%, $n=3$ ) (Baker et al., 2009; Feagan et al., 2004; Velasquez, Eastman, \& Masiunas, 2005), 'community pride' $(12.5 \%, n=3)$ (A. J. Johnson, 2013; Payet et al., 2005; Savoie Roskos, 2017), and participation in special events or community activities hosted by the farmers market $(16.7 \%, n=4)$ (Eastwood et al., 1999; Grace et al., 2007; Hunt, 2007; Walkinshaw et al., 2018). Additionally, in 
Table 2. Summary of Articles Included in the Systematic Review that Focused on Sense of Community at Farmers Markets (FM) $(n=24)$

\begin{tabular}{|c|c|c|c|c|c|c|}
\hline Primary Author & $\begin{array}{l}\text { Publication } \\
\text { Date }\end{array}$ & $\begin{array}{c}\text { Data Collection } \\
\text { Approach }\end{array}$ & Study Location & Sample Size & $\begin{array}{c}\text { Majority Race/ } \\
\text { Ethnicity }\end{array}$ & $\begin{array}{l}\text { Income Level } \\
\text { (High, Middle, } \\
\text { Low) }\end{array}$ \\
\hline Alkon & 2011 & Mixed & California & $\begin{array}{l}\text { Interviews (21) } \\
\text { Surveys (100) }\end{array}$ & White, Asian & High \\
\hline Alonso & 2011 & Quantitative & Alabama & 356 & NR & NR \\
\hline Baker & 2009 & Quantitative & Vermont & 229 & White & Middle, High \\
\hline Buman & 2015 & Qualitative & $\begin{array}{c}\text { Large metropolitan } \\
\text { U.S. city }\end{array}$ & FM Shoppers $(n=38)$ & White & NR \\
\hline Colasanti & 2010 & Mixed & Michigan & $\begin{array}{l}\text { Focus Groups (63) } \\
\text { Surveys (953) }\end{array}$ & $\begin{array}{l}\text { White, Latina, } \\
\text { Arab Americans }\end{array}$ & Low \\
\hline Dailey & 2015 & Mixed & Pennsylvania & 47 & Hispanic & Low \\
\hline Eastwood & 1999 & Quantitative & Tennessee & NR & White & High \\
\hline Feagen & 2004 & Quantitative & Niagara (Canada) & 146 & NR & Middle \\
\hline Feagan & 2009 & Quantitative & Canada & 149 & NR & Middle \\
\hline Freedman & 2018 & Quantitative & Ohio & 270 SNAP shoppers & African American & Low \\
\hline Garner & 2015 & Qualitative & NR & 19 & NR & NR \\
\hline Grace & 2007 & Qualitative & Oregon & 108 & White & Low \\
\hline Hunt & 2007 & Quantitative & Maine & 297 & NR & Middle, High \\
\hline Johnson & 2013 & Qualitative & Canada & 20 & NR & NR \\
\hline McGuirt & 2014 & Qualitative & North Carolina & 62 & $\begin{array}{c}\text { African American, } \\
\text { White }\end{array}$ & Low \\
\hline Misyak & 2014 & Quantitative & Virginia & 52 & NR & Low \\
\hline O'Kane & 2016 & Qualitative & Australia & 20 & NR & NR \\
\hline Payet & 2005 & Mixed & Australia & $\begin{array}{c}128 \text { (100 FM shoppers; } \\
28 \text { vendors) }\end{array}$ & NR & NR \\
\hline Ritter & 2018 & Mixed & Washington & $\begin{array}{c}451 \\
\text { (400 SNAP-ed shoppers; } \\
51 \text { stakeholders) }\end{array}$ & White & Low \\
\hline Savoie Roskos & 2017 & Qualitative & Utah & 14 & White & Low \\
\hline Sommer & 1981 & Quantitative & California & 349 & NR & NR \\
\hline Valasquez & 2005 & Quantitative & Illinois & 60 & NR & NR \\
\hline Walkinshaw & 2018 & Mixed & Washington & $\begin{array}{c}n=545 \\
\text { SNAP-Ed Stakeholders } \\
(51) \\
\text { SNAP Participants (400) } \\
\text { FM Managers (94) }\end{array}$ & White & Low \\
\hline Wetherill & 2015 & Qualitative & Oklahoma & 64 & African American & Low \\
\hline
\end{tabular}

$50 \%$ of the articles $(n=12)$ (Colasanti et al., 2010;

Eastwood et al., 1999; Feagan \& Morris, 2009;

Freedman et al., 2018; Grace et al., 2007; Hunt, 2007; Misyak et al., 2014; O'Kane, 2016; Ritter, Walkinshaw, Quinn, Ickes, \& Johnson, 2018; Sommer, Herrick, \& Sommer, 1981; Velasquez et al., 2005; Wetherill \& Gray, 2015), the authors described the 'shopping atmosphere and/or environment' as either welcoming or unwelcoming, which served as a barrier to or facilitator of farmers market usage based on the shopper's perspective of the shopping atmosphere.

SOC Among Farmers Market Shoppers

Living with Low Incomes

Among articles that included populations living with low incomes $(n=10)$, authors reported that SOC operated as both a facilitator of and barrier to 
farmers market patronage. Sixty percent $(n=6)$ of the articles reported high SOC among farmers market shoppers living with low incomes. Of these articles, $66.6 \%(n=4)$ focused on primarily white participants. Related to SOC as a facilitator of market patronage, these articles cited a welcoming, fun atmosphere (Grace et al., 2007; Ritter et al., 2018; Walkinshaw et al., 2018), participation in children's activities (Grace et al., 2007; Walkinshaw et al., 2018), and increased community involvement (Dailey et al., 2015; McGuirt et al., 2014; Savoie Roskos, Wengreen, Gast, LeBlanc, \& Durward, 2017) as the primary facilitators of farmers market patronage among shoppers living with low incomes.

The remaining $40 \%(n=4)$ of articles reported low SOC among farmers market shoppers living with low incomes. Of these articles, $75 \%$ focused on BIPOC, and one did not report race or ethnicity of participants. These articles cited SOC features such as an uncomfortable atmosphere (Colasanti et al., 2010; Misyak et al., 2014), distrust of vendors (Colasanti et al., 2010), and an unwelcome shopping environment (Colasanti et al., 2010; Freedman et al., 2018; Wetherill \& Gray, 2015) as primary barriers to farmers market patronage. Table 3 provides a summary of these findings.

\section{SOC Among Farmers Market Shoppers Living with} Middle to High Incomes

Among articles that included populations living with middle to high incomes $(n=6)$, SOC served

Table 3. Summary of Articles Related to Sense of Community Among Farmers Market (FM) Shoppers Living with Low Incomes ( $n=10)$

\begin{tabular}{|c|c|c|c|c|c|}
\hline $\begin{array}{l}\text { Primary } \\
\text { Author }\end{array}$ & $\begin{array}{l}\text { Publication } \\
\text { Year }\end{array}$ & Study Location & $\begin{array}{l}\text { Sample Size/ } \\
\text { Population }\end{array}$ & $\begin{array}{l}\text { Race/ } \\
\text { Ethnicity }\end{array}$ & Results Related to SOC at Farmers Markets \\
\hline \multicolumn{6}{|c|}{ High SOC $(\mathrm{n}=6)$} \\
\hline \multirow[t]{2}{*}{ Dailey } & 2015 & Pennsylvania & 47 & Hispanic & $\begin{array}{l}\text { Participants reported in the post program survey that } \\
\text { Healthy Options offered opportunities for social } \\
\text { interaction. }\end{array}$ \\
\hline & & & & & $\begin{array}{l}81 \% \text { of survey participants stated that farmers markets } \\
\text { gave them a chance to hang out with people in their } \\
\text { community }\end{array}$ \\
\hline Grace & 2007 & Oregon & 108 & White & $\begin{array}{l}\text { Occasional shoppers (shopped at a Portland market } \\
\text { more than once- } 43 \% \text { of sample) were likely to mention } \\
\text { the fun atmosphere and sense of community within } \\
\text { Portland's markets as the top reason for using them. } \\
\text { This included comments about the social interaction with } \\
\text { other shoppers, music, and activities for kids. }\end{array}$ \\
\hline \multirow[t]{2}{*}{ McGuirt } & 2014 & North Carolina & 62 & $\begin{array}{l}\text { African } \\
\text { American, } \\
\text { White }\end{array}$ & $\begin{array}{l}\text { Participants mentioned that they commonly went to shop } \\
\text {, at local food sources with their family members or } \\
\text { friends, and that experiences with home-grown produce } \\
\text { were often very social in nature. }\end{array}$ \\
\hline & & & & & $\begin{array}{l}\text { The women also mentioned interacting with the producer } \\
\text { as a positive aspect of the farmers market shopping } \\
\text { experience. }\end{array}$ \\
\hline \multirow[t]{2}{*}{ Ritter } & 2018 & Washington & $\begin{array}{c}451 \\
\text { (400 SNAP- } \\
\text { Ed shoppers; } \\
51 \text { stake- } \\
\text { holders) }\end{array}$ & White & $\begin{array}{l}\text { A large majority agreed that FMs are comfortable } \\
\text { ( } n=181 ; 92 \%) \text {, easy to navigate ( } n=175 ; 89 \%) \\
\text { welcoming to all ( } n=180 ; 91 \%) \text {, and affordable }(n=160 ; \\
81 \%) \text {. }\end{array}$ \\
\hline & & & & & $\begin{array}{l}\text {...respondents referred to the community feeling and } \\
\text { friendliness of FMs. }\end{array}$ \\
\hline $\begin{array}{l}\text { Savoie } \\
\text { Roskos }\end{array}$ & 2017 & Utah & 14 & White & $\begin{array}{l}\text { Community involvement and support was important for } \\
\text { many participants. }\end{array}$ \\
\hline
\end{tabular}


Journal of Agriculture, Food Systems, and Community Development

ISSN: 2152-0801 online

https:// foodsystemsjournal.org

\begin{tabular}{|c|c|c|c|c|c|}
\hline $\begin{array}{l}\text { Primary } \\
\text { Author }\end{array}$ & $\begin{array}{c}\text { Publication } \\
\text { Year }\end{array}$ & Study Location & $\begin{array}{l}\text { Sample Size/ } \\
\text { Population }\end{array}$ & $\begin{array}{l}\text { Race/ } \\
\text { Ethnicity }\end{array}$ & Results Related to SOC at Farmers Markets \\
\hline \multicolumn{6}{|c|}{ Low SOC $(n=4)$} \\
\hline Colasanti & 2010 & Michigan & $\begin{array}{c}\text { Focus Groups } \\
\text { (63) } \\
\text { Surveys (953) }\end{array}$ & $\begin{array}{l}\text { White, } \\
\text { Latina, } \\
\text { Arab } \\
\text { Americans }\end{array}$ & $\begin{array}{l}\text { [Rural, Latina women / young mothers] Felt they were } \\
\text { distrusted by vendors and atmosphere was unfriendly for } \\
\text { children } \\
\text { The women in this group also felt that they themselves } \\
\text { were disrespected by the vendors. One woman } \\
\text { described how she felt like she was being watched } \\
\text { whenever she went to the farmers market and others } \\
\text { agreed that they had had similar experiences. }\end{array}$ \\
\hline Freedman & 2018 & Ohio & $\begin{array}{l}270 \text { SNAP } \\
\text { shoppers }\end{array}$ & $\begin{array}{l}\text { African } \\
\text { American }\end{array}$ & $\begin{array}{l}\text { Social connectedness to FMs was significantly, but } \\
\text { inversely, related to FM shopping frequency. } \\
\text { Every one-unit increase in social connectedness to FMs } \\
\text { is associated with } 15 \% \text { reduction in the frequency of FM } \\
\text { use } \\
\text { For this group, there is a chance that visiting the FM } \\
\text { resulted in a negative social experience contributing to } \\
\text { their decisions to discontinue FM shopping. }\end{array}$ \\
\hline Misyak & 2014 & Virginia & 52 & NR & $\begin{array}{l}\text { SNAP-Ed clients listed "uncomfortable atmosphere" as a } \\
\text { barrier to FM usage. }\end{array}$ \\
\hline Wetherill & 2015 & Oklahoma & 64 & $\begin{array}{l}\text { African } \\
\text { American }\end{array}$ & $\begin{array}{l}\text { [Participants stated] “It is not our kind of environment. } \\
\text { Some people don't like that kind of environment." } \\
\text { “I am not going to lie; it mainly has to do with race to be } \\
\text { honest. I see more Caucasian people going to farmers } \\
\text { markets than African American. 'Oh... I want a fresh pack } \\
\text { of carrots.' No, you're gonna see Susie and Harry and } \\
\text { the kids picking up a pack of fresh carrots from the } \\
\text { farmer's market." }\end{array}$ \\
\hline
\end{tabular}

primarily as a facilitator of farmers market patronage, with $83 \%(n=5)$ of these articles reporting high SOC. These articles cited positive social benefits (Baker et al., 2009; Feagan et al., 2004; Feagan \& Morris, 2009; Hunt, 2007), a fun shopping environment (Eastwood et al., 1999; Feagan et al., 2004; Hunt, 2007), and the friendliness of the market (Hunt, 2007) as SOC facilitators of farmers market patronage.

Among articles specifically dedicated to SOC among farmers market shoppers living with middle to high incomes, only one noted that SOC at farmers market may differ based on race and ethnicity. In their study assessing inclusion at farmers markets among Asian and white patrons in California, Alkon and McCullen (2011) commented that white patrons may feel more included in farmers markets than BIPOC. They concluded that participating in shared common interests and community activities among farmers market shoppers and vendors may contribute to a feeling of inclusion at local farmers markets. Given these social activities were primarily attended by white community members, it left room for BIPOC within the community to feel excluded from the farmers market social experience (Alkon \& McCullen, 2011). Table 4 provides a summary of these findings.

\section{SOC Among Farmers Market Shoppers With Non-specified Income}

Income levels of participants were not specified in the remaining eight articles, however, results from these studies suggest that SOC plays an important role in farmers market patronage. The eight remaining studies suggested that farmers markets are more than just venues to purchase groceries and that a friendly, welcoming atmosphere (Alonso \& O’Neill, 2011; McGuirt et al., 2014; Payet et al., 
2005; Sommer et al., 1981; Velasquez et al., 2005) and positive social connections with other patrons and farmers market vendors (Alonso \& O’Neill, 2011; Buman et al., 2015; Garner, 2015; A. J.
Johnson, 2013; McGuirt et al., 2014; O'Kane, 2016) were primary driving factors for farmers market patronage. Table 5 provides a summary of these findings.

Table 4. Summary of Articles Related to Sense of Community Among Farmers Market (FM) Shoppers Lliving with Middle to High Incomes $(n=6)$

\begin{tabular}{cccc}
\hline & & Sample \\
& Publication & Size/ & Race/ \\
Primary Author & Year & Study Location & Population \\
Ethnicity & Results Related to SOC at Farmers Markets
\end{tabular}

\begin{tabular}{|c|c|c|c|c|c|}
\hline \multicolumn{6}{|c|}{ High SOC $(\mathrm{n}=5)$} \\
\hline Baker & 2009 & Vermont & 229 & White & $\begin{array}{l}\text { Social benefits* [were] listed as an important reason to } \\
\text { visit the market } * \text { Social benefits include a good place to } \\
\text { see friends and family, a good place to meet people, a } \\
\text { good place to take visitors. }\end{array}$ \\
\hline
\end{tabular}

\begin{tabular}{lcccc}
\hline Eastwood & 1999 & Tennessee & NR & White \\
\hline Feagen & 2004 & $\begin{array}{c}\text { Niagara } \\
\text { (Canada) }\end{array}$ & 146 & NR
\end{tabular}

Special events were a draw for just under one-third of Knox County shoppers. Shoppers were more likely to have checked...atmosphere as reasons for shopping.

Results from Port Colborne indicate greater emphasis on voiced themes like 'ambience', 'atmosphere', 'talking to people and farmers', 'people and friends', 'it's a peoplebonding place', 'I like the activity', 'I like to talk to the growers', than at the other two markets, but it is useful to note that the other market shoppers voiced similar kinds of sociocultural satisfactions that they associate with their farmers market experience.

\begin{tabular}{|c|c|c|c|c|c|}
\hline Feagan & 2009 & Canada & 149 & NR & $\begin{array}{l}\text { Brantford FM patrons identified their shopping } \\
\text { experience as strongly associated with the convivial } \\
\text { quality of the social and cultural interaction at the FM. } \\
\text { “...we love it because it is the fabric of the community. } \\
\text { Price isn't that much of a concern because again it's the } \\
\text { whole social aspect, and the culture of eating." }\end{array}$ \\
\hline Hunt & 2007 & Maine & 297 & NR & $\begin{array}{l}\text { Social factors, such as having fun at the market and } \\
\text { interacting with farmers, are important aspects of } \\
\text { shopping at farmers markets. Nearly all respondents } \\
\text { (98\%) had fun at the farmers markets. More than half of } \\
\text { the survey respondents (59\%) make the farmers market } \\
\text { a family event. }\end{array}$ \\
\hline
\end{tabular}

The social atmosphere, friendliness of the markets, and the ability for consumers to meet other people that they know indicate that community interactions are part of shopping at a farmers market.

\begin{tabular}{|c|c|c|c|c|c|}
\hline \multicolumn{6}{|c|}{ Low SOC $(n=1)$} \\
\hline \multirow[t]{2}{*}{ Alkon } & 2011 & California & $\begin{array}{l}\text { Interviews } \\
\quad(21) \\
\text { Surveys } \\
(100)\end{array}$ & $\begin{array}{l}\text { White, } \\
\text { Asian }\end{array}$ & $\begin{array}{l}\text { Farmers markets such as those we study emphasize the } \\
\text { importance of building community but are often unaware } \\
\text { that they define community in a way that draws in whites } \\
\text { while pushing away people of color. }\end{array}$ \\
\hline & & & & & $\begin{array}{l}\text { The first author has overheard discussions between } \\
\text { vendors and shoppers who have run into each other } \\
\text { hiking, or who recognize the places and events depicted } \\
\text { on one another's t-shirts and canvas shopping bags. This } \\
\text { creates a kind of insider ambiance, in which those who } \\
\text { know the wider scene, who tend to be white, feel } \\
\text { welcome while those who do not may feel excluded. }\end{array}$ \\
\hline
\end{tabular}


Table 5. Summary of Articles Related to Sense of Community Among Shoppers with Non-Specified Income $(n=8)$

\begin{tabular}{|c|c|c|c|c|c|}
\hline $\begin{array}{l}\text { Primary } \\
\text { Author } \\
\end{array}$ & $\begin{array}{c}\text { Publication } \\
\text { Year }\end{array}$ & $\begin{array}{c}\text { Study } \\
\text { Location }\end{array}$ & $\begin{array}{c}\text { Sample Size/ } \\
\text { Population }\end{array}$ & $\begin{array}{c}\text { Race/ } \\
\text { Ethnicity }\end{array}$ & Results Related to SOC at Farmers Markets \\
\hline Alonso & 2011 & Alabama & 356 & NR & $\begin{array}{l}\text { The importance of socializing, social interaction, or } \\
\text { 'embeddedness' as some researchers have noted was } \\
\text { also clearly higher among respondents from the Langdale } \\
\text { Mill (a more rural environment). }\end{array}$ \\
\hline Buman & 2015 & $\begin{array}{l}\text { Large } \\
\text { Metropolitan } \\
\text { US City }\end{array}$ & $\begin{array}{l}\text { FM Shoppers } \\
\qquad(n=38)\end{array}$ & White & $\begin{array}{l}\text { "This is the most exciting place in town...this is the place } \\
\text { you can meet people like you can't meet any place else." } \\
\text { Perhaps more interesting was that other contextual factors } \\
\text { such as product presentation and social interactions were } \\
\text { also deemed important both in terms of frequency of } \\
\text { coded elements and consensus among shoppers. }\end{array}$ \\
\hline Garner & 2015 & NR & 19 & NR & $\begin{array}{l}\text { In my interviews with shoppers, there proved to be a } \\
\text { spectrum of desires for social interaction. On the extreme } \\
\text { social end of the spectrum, there were the highly social } \\
\text { shoppers who wanted to make friends with farmers and } \\
\text { other shoppers. On the less social end of the spectrum, } \\
\text { there were shoppers who purchased their products quickly } \\
\text { and exited the market. } \\
\text { Different consumers and farmers possess varying degrees } \\
\text { of community connectedness. }\end{array}$ \\
\hline Johnson & 2013 & Canada & 20 & NR & $\begin{array}{l}\text { Themes drawn from the data suggest that market } \\
\text { participants shared a collective sense of connection to the } \\
\text { people who form the community. In addition, the activities } \\
\text { that occur in the space reinforce the connection between } \\
\text { community members. Connection to the people and } \\
\text { connection to the activities, therefore, are important } \\
\text { characteristics of this consumption community. } \\
\text { For most participants, the interactions between the } \\
\text { vendors and the buyers created a positive atmosphere and } \\
\text { sense of community. }\end{array}$ \\
\hline O'Kane & 2016 & Australia & 20 & NR & $\begin{array}{l}\text { Shopping, rather than being an imposition, is an enjoyable } \\
\text { and relaxing event, where these farmers market devotees } \\
\text { become immersed in the atmosphere, happily devoting } \\
\text { their social time to developing meaningful relationships } \\
\text { with the vendors who provide their food. }\end{array}$ \\
\hline Payet & 2005 & Australia & $\begin{array}{l}128 \text { (100 FM } \\
\text { shoppers; } 28 \\
\text { vendors) }\end{array}$ & NR & $\begin{array}{l}\text { A high proportion of consumers had an increased sense of } \\
\text { community pride (92\%). } \\
\text { The market experience has become a vital part of the } \\
\text { stallholders' and the community's social interaction and } \\
\text { has fostered a sense of civic pride. }\end{array}$ \\
\hline Sommer & 1981 & California & 349 & NR & $\begin{array}{l}\text { The farmers market was perceived by its shoppers as a } \\
\text { more friendly, personal, rural, smaller, and happier setting } \\
\text { than was the supermarket by its shoppers. }\end{array}$ \\
\hline Valasquez & 2005 & Illinois & 60 & NR & $\begin{array}{l}\text { Consumers at Urbana also visited the market to support } \\
\text { local farmers ( } 87 \%) \text { and enjoyed the informational/social } \\
\text { atmosphere (90\%). } \\
57 \% \text { of Collinsville shoppers enjoyed the information/ } \\
\text { social atmosphere. }\end{array}$ \\
\hline
\end{tabular}




\section{Discussion}

The purpose of this paper was to conduct a review of farmers market literature to summarize and document what is empirically known about SOC as an asset or barrier to farmers market usage for shoppers living with low and middle to high incomes. Our findings extend the existing literature by specifically describing and summarizing SOC and how SOC functions as a barrier to and facilitator of farmers market usage. Prior studies have not focused exclusively on SOC, but rather on a blend of social, environmental, spatial, and economic considerations (Freedman et al., 2016). Our study was the first to describe SOC as it relates to shopping behaviors as a specific construct, how SOC may function differently by income level, and how SOC may function differently by race and/or ethnicity.

\section{SOC as a Facilitator of Farmers Market Usage} Our systematic review uncovered that SOC can play an important role as a facilitator of farmers market usage among people with all income levels; the most noted SOC facilitators were a welcoming and fun shopping atmosphere and social interactions experienced at farmers markets. Several studies indicated that for shoppers living with low incomes, special events and children's activities that focused on their needs were facilitators of famers' market patronage. For example, Grace et al. (2007) noted that shoppers at a farmers market in Portland, Oregon listed a fun atmosphere and social interaction at markets as the top reasons for shopping there. Activities mentioned in the article included conversing with other shoppers, live music events, and activities for kids.

Additionally, among shoppers living with middle to high incomes, 'social and community benefits' were noted as primary facilitators of farmers markets usage. Social benefits described by these shoppers included socializing with friends, conversing with market vendors, and meeting new community members. Several studies noted that these social benefits are so powerful, that they may be more important to more affluent shoppers than the cost of goods available at the market. For example, in a study by Feagan et al. (2009) assessing farmers market shoppers in the Ontario region of Canada, participants stated "...we love it because it is the fabric of the community. Price isn't that much of a concern because again it's the whole social aspect, and the culture of eating (p. 239). This indicates that placing emphasis on creating a positive and welcoming atmosphere may be a more important community consideration to attract potential farmers market customers than considerations of farmers market product cost, at least for shoppers living with middle to high incomes.

\section{SOC as a Barrier to Farmers Market Usage}

For shoppers living with low incomes who also receive federal food assistance, negative shopping atmosphere was listed as a primary barrier to farmers market usage. Shoppers who receive SNAP benefits viewed farmers markets as exclusive spaces that did not create a welcoming environment for people living with lower incomes. For example, in a study by Misyak et al. (2014), SNAP Education (SNAP-Ed) clients listed an "uncomfortable atmosphere" as a primary barrier to farmers market usage. Russomanno and Jabson's (2016) qualitative findings validate these shoppers' perceptions; market managers at East Tennessee farmers markets reported that vendors often showed resistance toward SNAP recipients. In the study, market managers disclosed that vendors did not support SNAP incentive programs, and that vendors often had misconceptions of SNAP recipients as a "lower class people." One manager stated, “They [vendors] don't necessarily want to attract the kind of people that they believe would have access to SNAP” (Russomanno \& Jabson, 2016, p. 2834). These findings are also consistent with a previous systematic review by Freedman et al. (2016) that reported an unwelcome shopping environment as one of several major barriers for farmers market shoppers living with low incomes.

Many studies that reported high SOC among farmers market shoppers focused on white patrons. However, SOC was consistently low across all income levels for BIPOC. SOC was lowest among studies that reported on shopper experiences of BIPOC living with low incomes. Colasanti et al. (2010) noted that Latina shoppers living with low incomes in Michigan reported feeling disrespected 
and uncomfortable at local farmers markets. This study reported: "The women in this group [young Latina women] felt that they were disrespected by the vendors. One woman described how she felt like she was being watched whenever she went to the farmers market and others agreed that they had had similar experiences" (Colasanti et al, 2010, p. 231). In an Oklahoma based study, Wetherhill and colleagues (2017) had similar findings among lowincome Black shoppers. One participant noted, "I am not going to lie; it mainly has to do with race to be honest. I see more Caucasian people going to farmers markets than African American. 'Oh... I want a fresh pack of carrots.' No, you're gonna see Susie and Harry and the kids picking up a pack of fresh carrots from the farmer's market" (Wetherhill et al, 2017, p. 7). These negative social experiences contributed to a lowered SOC and acted as barriers to using farmers markets among BIPOC living with low incomes. These results support the previous notion that farmers markets are exclusionary spaces that are primarily designed for more affluent white shoppers (Alkon \& McCullen, 2011; Freedman et al., 2016; Wolf, Spittler, \& Ahern, 2005) and are especially pertinent given that, in FY 2018, 40.6\% of SNAP recipients identified as BIPOC (USDA, 2019a).

If farmers markets are to be viewed as spaces that contribute to improving food access by delivering high quality, local produce to diverse shoppers, including shoppers living with low incomes and/or BIPOC, then SOC is something that farmers markets should carefully consider and deliberately address. Farmers market managers and community leaders should consider who is being attracted to their local markets and how the shopping environment may be inclusive or exclusive to members of economically, racially and/or ethnically diverse groups. Considerations of diverse racial and ethnic identities should be reflected in farmers market promotional materials and participation from vendors of diverse identities should be encouraged.

In addition, farmers markets organizers should consider developing partnerships and relationships with community organizers that work with people living with low incomes and racial and/or ethnic minority groups to enhance SOC at farmers mar- kets. For example, in their study assessing farmers market shopping behaviors among SNAP-Ed participants in Washington State, Walkinshaw and colleagues (2018) found that participants who partook in one or more farmers market activities coordinated by the local SNAP-Ed office and associated community-based organizations (e.g., local health departments, extension programs) had a higher probability of shopping at farmers markets when compared with those that participated in no activities. They concluded that SNAP participants who participate more frequently in SNAP-Ed farmers market activities also shop more often at farmers markets. Shopping frequency at farmers market was beneficial to SNAP participants as it was associated with increased consumption of fruits and vegetables (Walkinshaw et al., 2018).

\section{Limitations}

Our review has limitations. Several publications included in our review $(n=12)$ did not include key demographic information about study participants, therefore it was impossible to assess the SOC experiences by income and/or race or ethnicity. Lack of standardization in the assessment and reporting of income and race and/or ethnicity limited our ability to draw comparisons in SOC among farmers market shoppers using these measures. Additionally, all studies included in our systematic review were cross-sectional and observational. None of the studies involved documenting and testing shoppers' experiences over time, nor did they test an intervention to improve SOC for shoppers. These study characteristics limit what we can say about the impact of SOC on sustained shopping behavior.

\section{Conclusion}

Findings from this systematic review suggest that SOC plays an important role in who shops at farmers markets and at what frequency. When designing local farmers markets and associated activities, farmers market managers and community leaders should consider SOC. Our results suggest that offering special events, especially family-friendly activities, may be attractive additions to the farmers market experience for shoppers at all income levels. 
Additionally, farmers market managers and community leaders should take extra precaution when implementing markets and associated activities to create an inclusive environment for shoppers of diverse income and racial and/or ethnic identities. The responses provided by BIPOC SNAP recipients suggest that vendors at farmers markets may be creating an unwelcome and uncomfortable shopping environment. Farmers market managers should consider conducting training programs for market vendors to combat any negative stereotypes and perceptions of SNAP recipients. Lastly, farmers markets should consider adding BIPOC and/or people with diverse income levels to their planning committees or executive boards to ensure a range of community voices and perspectives are represented.

\section{Special Pandemic Considerations}

During widespread crises, such as the COVID-19 pandemic, SOC may be even more salient and vital to farmers markets' efforts to retain and attract people living with low incomes and BIPOC. While many farmers markets around the country are still operational, the social landscapes of markets have been altered, with many practicing social distancing guidelines, limiting the number of shoppers, and requiring masks during shopping hours (Farmers Market Coalition, 2020a). These extra precautions mean that many of the social activities described by authors and included in our systematic review have been paused indefinitely. However, SOC can still be established by offering a friendly, safe, and inclusive shopping environment. For example, many farmers markets around the country are creating a modified SOC among shoppers by offering takehome activities for children and to-go samples of various farmers market products (Minnesota Farmers' Market Association, 2020; Nourish Knoxville, 2020). Additionally, while maintaining appropriate social distancing at farmers markets, shoppers are encouraged to get outdoors and interact and converse with local area farmers, neighbors, and community members, which may be a welcome change for some farmers market shoppers (C. Johnson, 2020; Massachusetts Municipal Association, 2020). In a time that is currently dominated by virtual meetings, limited contact, and computer screens, the ability to engage with other shoppers and vendors may help contribute to a positive outlook and sense of normalcy for some. Creating a welcoming and positive space at markets during the pandemic may be a useful tool to retain existing shoppers and attract new ones.

\section{Considerations for Future Research}

Researchers interested in the influence of SOC on farmers markets participation, patterns of shoppers who are BIPOC and/or living with low incomes, use of SNAP benefits at farmer's markets, and other shopping and related behaviors should consider assessing SOC in their studies. The dearth of literature on this topic suggests that there is room for and benefit from additional assessment and inclusion. For example, researchers interested in understanding low-income and/or BIPOC shoppers' experiences at farmers markets, or their SOC at farmers markets, or reasons for not shopping at farmers markets, could capture these experiences using primary data collected from farmers market shoppers through methods such as focus groups or semi-structured interviews. Future work in this area also lends itself to a Community Based Participatory Research (CBPR) approach (Minkler, Thompson, Bell, \& Rose, 2001; Roussos \& Fawcett, 2000). CBPR researchers, in collaboration with community members, could expand what is known about SOC and its role in farmers markets patronage among shoppers who are BIPOC and/or living with low incomes. Approaches for measuring SOC that facilitate participants' direct and engaged perspectives include, but are not limited to, Photovoice or Videovoice methods. These methods would allow community organizers and farmers market managers to see their market through the lens of the people who shop there and add to our understanding about SOC and its influence on shopping behaviors and customer experiences.

\section{References}

Alkon, A. H., \& McCullen, C. G. (2011). Whiteness and farmers markets: Performances, perpetuations... contestations? Antipode, 43(4), 937-959. https://doi.org/10.1111/j.1467-8330.2010.00818.x 
Alonso, A. D., \& O’Neill, M. A. (2011). A comparative study of farmers' markets visitors' needs and wants: The case of Alabama. International Journal of Consumer Studies, 35(3), 290-299. https://doi.org/10.1111/j.1470-6431.2010.00931.x

Appalachian Sustainable Agriculture Project. (2012). Farmers markets for all: Exploring barriers and opportunities for increasing fresh food access by connecting low-income communities with farmers markets. Retreieved from https://asapconnections.org/downloads/asap-farmers-markets-for-all-full-report.pdf/

Baker, D., Hamshaw, K., \& Kolodinsky, J. (2009). Who shops at the market? Using consumer surveys to grow farmers' markets: Findings from a regional market in northwestern Vermont. Journal of Extension, 47(6), 1-9. https://archives.joe.org/joe/2009december/a2.php

Briggs, S. (2010). Real food, real choice: Connecting SNAP recipients with farmers markets. Community Food Security Coalition. Retrieved from http://foodsecurity.org/pubs/realfoodrealchoice snap farmersmarkets/

Buman, M. P., Bertmann, F., Hekler, E. B., Winter, S. J., Sheats, J. L., King, A. C., \& Wharton, C. M. (2015). A qualitative study of shopper experiences at an urban farmers' market using the Stanford Healthy Neighborhood Discovery Tool. Public Health Nutrition, 18(6), 994-1000. https://doi.org/10.1017/S136898001400127X

Center on Budget and Policy Priorities. (2019). SNAP Retailers Database. Retrieved from https://www.cbpp.org/snap-retailers-database

Colasanti, K. J., Conner, D. S., \& Smalley, S. B. (2010). Understanding barriers to farmers' market patronage in Michigan: Perspectives from marginalized populations. Journal of Hunger \& Environmental Nutrition, 5(3), 316-338. https://doi.org/10.1080/19320248.2010.504097

Dailey, A. B., Hess, A., Horton, C., Constantian, E., Monani, S., Wargo, B., Davidson, K., \& Gaskin, K. (2015). Healthy options: A community-based program to address food insecurity. Journal of Prevention and Intervention in the Community, 43(2), 83-94. https://doi.org/10.1080/10852352.2015.973248

DeLind, L. B. (1993). Market niches,'cul de sacs', and social context: Alternative systems of food production. Culture \& Agriculture, 13(47), 7-12. https://doi.org/10.1525/cuag.1993.13.47.7

Eastwood, D. B., Brooker, J. R., \& Gray, M. D. (1999). Location and other market attributes affecting farmer's market patronage: The case of Tennessee. Journal of Food Distribution Research, 30, 63-72. https://doi.org/10.22004/ag.econ.26789

Evans, A. E., Jennings, R., Smiley, A. W., Medina, J. L., Sharma, S. V., Rutledge, R., Stigler, M. H., \& Hoelscher, D. M. (2012). Introduction of farm stands in low-income communities increases fruit and vegetable among community residents. Health Place, 18(5), 1137-1143. https://doi.org/10.1016/j.healthplace.2012.04.007

Fair Food Network. (2018). Double up food bucks. Retrieved from https:/ / fairfoodnetwork.org/projects/double-up-food-bucks/

Farmer, J. R., Chancellor, C., Gooding, A., Shubowitz, D., \& Bryant, A. (2011). A tale of four farmers markets: Recreation and leisure as a catalyst for sustainability. Journal of Park and Recreation Administration, 29(3). https://js.sagamorepub.com/jpra/article/view/2252

Farmers Market Coalition. (2020a). Farmers markets respond to COVID-19 — daily updates and announcements. Retrieved from https://farmersmarketcoalition.org/farmers-markets-covid19/

Farmers Market Coalition. (2020b). Supplemental nutrition assistance program (SNAP). Retrieved from https:// farmersmarketcoalition.org/advocacy/snap/

Feagan, R., Morris, D., \& Krug, K. (2004). Niagara region farmers' markets: Local food systems and sustainability considerations. Local environment, 9(3), 235-254. https://doi.org/10.1080/1354983042000219351

Feagan, R. B., \& Morris, D. (2009). Consumer quest for embeddedness: A case study of the Brantford Farmers' Market. International Journal of Consumer Studies, 33(3), 235-243. https://doi.org/10.1111/j.1470-6431.2009.00745.x

Fisher, A. (1999). Hot peppers and parking lot peaches: Evaluating farmers' markets in low income communities. Community Food Security Coalition. Retrieved from https://foodsecurity.org/HotPeppersPeaches.pdf

Flamm, L. J. (2011). Barriers to EBT use at farmers' markets: Lessons in empowerment evaluation from rural Ohio. Journal of Hunger \& Environmental Nutrition, 6(1), 54-63. https://doi.org/10.1080/19320248.2011.549801 
Freedman, D. A., Lee, E., Ohri-Vachaspati, P., Trapl, E., Borawski, E., Bess, K., \& Flocke, S. (2018). Predictors of farmers' market shopping among people receiving supplemental nutrition assistance program benefits. American Journal of Community Psychology, 61(3-4), 488-499. https://doi.org/10.1002/ajcp.12245

Freedman, D. A., Vaudrin, N., Schneider, C., Trapl, E., Ohri-Vachaspati, P., Taggart, M., .. . Flocke, S. (2016). Systematic review of factors influencing farmers' market use overall and among low-income populations. Journal of the Academy of Nutrition and Dietetics, 116(7), 1136-1155. https://doi.org/10.1016/j.jand.2016.02.010

Garner, B. (2015). Communication at farmers' markets: Commodifying relationships, community and morality. Journal of Creative Communications, 10(2), 186-198. https://doi.org/10.1177/0973258615597407

Grace, C., Grace, T., Becker, N., \& Lyden, J. (2007). Barriers to using urban farmers' markets: an investigation of food stamp clients' perceptions. Journal of Hunger \& Environmental Nutrition, 2(1), 55-75.

https://doi.org/10.1080/19320240802080916

Guzman, G. (2019, September 26). New data show income increased in 14 states and 10 of the largest metros. U.S. Census Bureau. Retrieved from https://www.census.gov/library/stories/2019/09/us-median-household-income-up-in-2018-from-2017.html

Horsley, T., Dingwall, O., \& Sampson, M. (2011). Checking reference lists to find additional studies for systematic reviews. Cochrane Database of Systematic Reviews, 8. https://doi.org/10.1002/14651858.MR000026.pub2

Hunt, A. R. (2007). Consumer interactions and influences on farmers' market vendors. Renewable Agriculture and Food Systems, 22(1), 54-66. https://doi.org/10.1017/S1742170507001597

Jilcott Pitts, S. B., Wu, Q., McGuirt, J. T., Crawford, T. W., Keyserling, T. C., \& Ammerman, A. S. (2013). Associations between access to farmers' markets and supermarkets, shopping patterns, fruit and vegetable consumption and health indicators among women of reproductive age in eastern North Carolina, U.S.A. Public Health Nutrition, 16(11), 1944-1952. https://doi.org/10.1017/s1368980013001389

Johnson, A. J. (2013). 'It's more than a shopping trip': Leisure and consumption in a farmers' market. Annals of Leisure Research, 16(4), 315-331. https://doi.org/10.1080/11745398.2013.846226

Johnson, C. (2020, May 12). Supporting farmers markets in the time of COVID-19. Food Blog, UC Divison of Agriculture and Natural Resources. Retrieved from https://ucanr.edu/blogs/blogcore/postdetail.cfm?postnum=41443

Markowitz, L. (2010). Expanding access and alternatives: Building farmers' markets in low-income communities. Food and Foodways, 18(1-2), 66-80. https://doi.org/10.1080/07409711003708512

Massachusetts Municipal Association. (2020, May 14). With a different look, farmers markets march on amid COVID crisis. Retrieved from https://www.mma.org/with-a-different-look-farmers-markets-march-on-amid-covid-crisis/

McGill, N. (2015). Farmers markets bring healthy choices to low-income shoppers: USDA program benefits SNAP users. The Nation's Health, 45(1) 1-16. Retrieved from https://www.thenationshealth.org/content/45/1/1.2

McGuirt, J. T., Ward, R., Elliott, N. M., Bullock, S. L., \& Jilcott Pitts, S. B. (2014). Factors influencing local food procurement among women of reproductive age in rural eastern and western North Carolina, USA. Journal of Agriculture, Food Systems, and Community Devolpment, 4(4), 143-154. https://doi.org/10.5304/jafscd.2014.044.004

McMillan, D. W., \& Chavis, D. M. (1986). Sense of community: A definition and theory. Journal of Community Psychology, 14(1), 6-23. https://doi.org/10.1002/1520-6629(198601)14:1<6::AID-JCOP2290140103>3.0.CO;2-I

Minkler, M., Thompson, M., Bell, J., \& Rose, K. (2001). Contributions of community involvement to organizationallevel empowerment: The federal healthy start experience. Health Education \& Behavior, 28(6), $783-807$. https://doi.org/10.1177/109019810102800609

Minnesota Farmers' Market Association. (2020). Guidance for Minnesota farmers' markets and vendors during the COVID-19 pandemic. Retrieved from https://www.mfma.org/Guidance-for-Markets

Misyak, S., Ledlie Johnson, M., McFerren, M., \& Serrano, E. (2014). Family nutrition program assistants’ perception of farmers' markets, alternative agricultural practices, and diet quality. Journal of Nutrition Education and Behavior, 46(5), 434-439. https://doi.org/10.1016/j.jneb.2014.02.011

Moher, D., Liberati, A., Tetzlaff, J., \& Altman, D. G. (2009). Preferred reporting items for systematic reviews and metaanalyses: The PRISMA statement. Annals of internal medicine, 151(4), 264-269.

https://doi.org/10.7326/0003-4819-151-4-200908180-00135 
Muniz, A. M., \& O'Guinn, T. C. (2001). Brand community. Journal of Consumer Research, 27(4), 412-432. https://doi.org/10.1086/319618

Nourish Knoxville. (2020). Nourish kids. Retrieved from https://www.nourishknoxville.org/programs/nourish-kids/

O'Kane, G. (2016). A moveable feast: Contemporary relational food cultures emerging from local food networks. Appetite, 105, 218-231. https://doi.org/10.1016/j.appet.2016.05.010

Olsho, L. E., Payne, G. H., Walker, D. K., Baronberg, S., Jernigan, J., \& Abrami, A. (2015). Impacts of a farmers' market incentive programme on fruit and vegetable access, purchase and consumption. Public Health Nutrition, 18(15), 27122721. https://doi.org/10.1017/s1368980015001056

Payet, J., Gilles, M., \& Howat, P. (2005). Gascoyne Growers Market: A sustainable health promotion activity developed in partnership with the community. The Australian Journal of Rural Health, 13(5), 309-314.

https://doi.org/10.1111/j.1440-1584.2005.00722.x

Plas, J. M., \& Lewis, S. E. (1996). Environmental factors and sense of community in a planned town. American Journal of Community Psychology, 24(1), 109. https://doi.org/10.1007/bf02511884

Project for Public Spaces. (2013). Farmers markets as a strategy to improve access to healthy food for low-income families and communities. Retrieved from https://www.pps.org/article/farmers-markets-as-a-strategy-to-improve-access-tohealthy-food-for-low-income-families-and-communities

Racine, E. F., Smith Vaughn, A., \& Laditka, S. B. (2010). Farmers' market use among African-American women participating in the Special Supplemental Nutrition Program for Women, Infants, and Children. Journal of American Dietetic Association, 110(3), 441-446. https://doi.org/10.1016/j.jada.2009.11.019

Rice, J. S. (2015). Privilege and exclusion at the farmers market: Findings from a survey of shoppers. Agriculture and Human V alues, 32(1), 21-29. https://doi.org/10.1007/s10460-014-9513-7

Ritter, G., Walkinshaw, L. P., Quinn, E. L., Ickes, S., \& Johnson, D. B. (2018). An assessment of perceived barriers to farmers' market access. Journal of Nutrition Education and Behavior, 51(1), 48-56. https://doi.org/10.1016/j.jneb.2018.07.020

Roussos, S. T., \& Fawcett, S. B. (2000). A review of collaborative partnerships as a strategy for improving community health. Annual Review of Public Health, 21(1), 369-402. https://doi.org/10.1146/annurev.publhealth.21.1.369

Ruelas, V., Iverson, E., Kiekel, P., \& Peters, A. (2012). The role of farmers' markets in two low income, urban communities. Journal of Community Health, 37(3), 554-562. https://doi.org/10.1007/s10900-011-9479-y

Russomanno, J., \& Jabson, J. M. (2016). Farmers' markets' uptake of food assistance programmes in East Tennessee, USA. Public Health Nutrition, 19(15), 2829-2837. https://doi.org/10.1017/s1368980016001038

Savoie Roskos, M. R. (2017). The role of farmers' market incentives on the fruit and vegetable intake and food security status of supplemental nutrition assistance program participants.(Accession Number AAI10101032) [Doctoral Dissertation, Utah State University]. PsycINFO database.

Savoie Roskos, M. R., Wengreen, H., Gast, J., LeBlanc, H., \& Durward, C. (2017). Understanding the experiences of low-income individuals receiving farmers' market incentives in the United States: A qualitative study. Health Promotion Practice, 18(6), 869-878. https://doi.org/10.1177/1524839917715438

Sommer, R., Herrick, J., \& Sommer, T. R. (1981). The behavioral ecology of supermarkets and farmers' markets. Journal of Environmental Psychology, 1(1), 13-19. https://doi.org/10.1016/S0272-4944(81)80014-X

Szmigin, I., Maddock, S., \& Carrigan, M. (2003). Conceptualising community consumption: Farmers' markets and the older consumer. British Food Journal, 105(8), 542-550. https://doi.org/10.1108/00070700310497291

The Food Trust. (2018). The food trust's food bucks network. Retrieved from http://thefoodtrust.org/what-we-do/foodbucks

U.S. Department of Agriculture. (2010). Supplemental Nutrition Assistance Program: Feasibility of Implementing Electronic Benefit Transfer Systems in Farmers' Markets. Retrieved from https://fns-prod.azureedge.net/sites/default/files/snap/Kohl--Feasibility.pdf

U.S. Department of Agriculture, Food and Nutrition Service [USDA FNS]. (2019a). Characteristics of Supplemental Nutrition Assistance Program Households: Fiscal Year 2018. Retrieved from https://www. fns.usda.gov/snap/characteristicssupplemental-nutrition-assistance-program-households-fiscal-year-2018 
U.S. Department of Agriculture, Agricultural Marketing Service [USDA AMS] (2019b). Local Food Directories: National Farmers Market Directory. Retrieved from https://www.ams.usda.gov/local-food-directories/farmersmarkets

Velasquez, C., Eastman, C., \& Masiunas, J. (2005). An assessment of Illinois farmers' market patrons' perceptions of locally-grown vegetables. Journal of Vegetable Science, 11(1), 17-26. https://doi.org/10.1300/J484v11n01 03

Walkinshaw, L. P., Quinn, E. L., Rocha, A., \& Johnson, D. B. (2018). An evaluation of Washington state SNAP-Ed farmers' market initiatives and SNAP participant behaviors. Journal of Nutrition Education Behavior, 50(6), 536-546. https://doi.org/10.1016/j.jneb.2018.01.003

Wetherill, M. S., \& Gray, K. A. (2015). Farmers' markets and the local food environment: identifying perceived accessibility barriers for SNAP consumers receiving temporary assistance for needy families (TANF) in an urban Oklahoma community. Journal of Nutrition Education and Behavior, 47(2), 127-133.e121. https://doi.org/10.1016/j.jneb.2014.12.008

Wetherill, M. S., Williams, M. B., \& Gray, K. A. (2017). SNAP-Based incentive programs at farmers' markets: adaptation considerations for temporary assistance for needy families (TANF) recipients. Journal of Nutr Educ Behav, 49(9), 743751.e741. https://doi.org/10.1016/i.jneb.2017.06.002

Wohlin, C. (2014). Guidelines for snowballing in systematic literature studies and a replication in software engineering. Association for Computing Machinery, 38, 1-10. https://dl.acm.org/doi/10.1145/2601248.2601268

Wolf, M., Spittler, A., \& Ahern, J. (2005). A profile of farmers' market consumers and the perceived advantages of produce sold at farmers' markets. Journal of Food Distribution Research, 36. https://doi.org/10.22004/ag.econ.26768

Young, C., Karpyn, A., Uy, N., Wich, K., \& Glyn, J. (2011). Farmers' markets in low income communities: Impact of community environment, food programs and public policy. Community Development, 42(2), 208-220. https://doi.org/10.1080/15575330.2010.551663

Young, C. R., Aquilante, J. L., Solomon, S., Colby, L., Kawinzi, M. A., Uy, N., \& Mallya, G. (2013). Improving fruit and vegetable consumption among low-income customers at farmers markets: Philly Food Bucks, Philadelphia, Pennsylvania, 2011. Preventing Chronic Disease, 10. https://doi.org/10.5888/pcd10.120356 